\title{
FIRLESS FIRWOES: HOW PREFERENCES CAN INTERFERE WITH THE THEOREMS OF INTERNATIONAL TRADE
}

\author{
Alan V. DEARDORFF* \\ University of Michigan, Ann Arbor, MI 48109, USA
}

Received April 1984, revised version received May 1985

\begin{abstract}
An example is presented of a two-country, two-factor, four-good trade model in which free trade causes factor prices to be drawn farther apart than they were in autarky. The example is equivalent to a two-good model with a double factor intensity reversal (FIR), and thus demonstrates that the problems associated with FIRs can arise in many dimensions without them. These problems include the undermining of other trade theorems as well, and can be avoided only by making some assumption about demand as well as about technology. For example, the model becomes well-behaved if preferences and technology are both CobbDouglas.
\end{abstract}

\section{Introduction}

It is well known that factor intensity reversals (FIRs) can play havoc with the theorems of the Heckscher-Ohlin-Samuelson (HOS) model of international trade. It is therefore customary to exclude FIRs by assumption, with or without a solid empirical basis for doing so. ${ }^{1}$ The standard $2 \times 2 \times 2$ HOS model then performs nicely. While other difficulties have sometimes arisen in efforts to extend theorems to higher dimensions, some success has been achieved, as surveyed by Ethier (1984). However, I would suggest that further extensions will be difficult, at least until we come to terms with the problems posed in two dimensions by FIRs. For the same kinds of problems also arise in many dimensions, even when FIRs themselves are absent. The problem is that certain properties of preferences among many goods can replicate arbitrarily closely the effects of FIRs. Thus, until we can find an acceptable

*This paper is based on Deardorff (1983), a short paper which failed to generate the interest I thought it deserved. In the spirit of the Washington bureaucracy, I have responded to the failure of that paper by making it larger and changing its name. I would like to thank Ted Bergstrom, Jon Eaton, Bob Stern and two anonymous referees for their helpful comments, as well as other members of the Research Seminar in International Economics at Michigan and those who participated in the trade theory conference at the University of Western Ontario, 17 March, 1984. Support in writing this paper was provided by the Ford Foundation.

${ }^{1}$ Minhas (1962) claimed to have identified enough empirically relevant FIRs to make the HOS model questionable. His methodology was criticized by a number of authors, surveyed by Bhagwati (1969), but Stern (1975) noted more recent work that leaves the empirical importance of FIRs still up in the air. 
regularity assumption that applies simultaneously to both technology and preferences, our efforts to characterize behavior in a many dimensional HOS model will be of only limited success.

The basis for these concerns consists of an example in section 2. Free trade in four goods between two countries with two factors can cause factor prices to move farther apart than in autarky. This occurs without FIRs, but for reasons best understood by looking first at a two-good model with a double FIR. The factor-price equalization theorem is violated in the extreme in this example, since there is not even a tendency toward factor prices being equalized. This is not a complete novelty, since Land (1959), with an assist by Stewart (1976), has also shown such an example. But in my example, unlike Land's, factor prices move apart in opposite directions, providing a more dramatic and easily understood picture of their effects.

These effects are discussed further in section 3, where I examine major propositions of pure trade theory. While some of these have been extended in various forms to higher dimensions, I argue that the intuition behind them all is undermined in this example. Thus, the example represents more than just a curious possibility. It goes to the heart of the economic intuition that has underlain trade theory since Heckscher (1919) and Ohlin (1933).

Their insight, as I understand it, was that factor prices are determined by factor scarcity, and that trade, by opening factor markets to indirect competition with factors abroad, alters this relative scarcity. Thus, a country's scarce factor is relatively expensive in autarky, earning the usual scarcity rent. With trade, however, the products produced by that scarce factor must compete with counterparts produced by the same factor abroad, where it is relatively more abundant. This trade erodes the scarcity rent of the factor, causing its originally high relative return to fall. Similarly, a country's relatively abundant factor will have its relatively low autarky price raised by trade, as it finds new markets for what it can best produce. Thus, the tendency for factor prices to converge with trade is a straightforward implication of supply and demand, and has nothing to do with the particular mathematical properties of homogeneous production functions that seem, almost coincidentally, to give rise in special cases to full factor-price equalization.

Given this strong economic reason for factor prices to converge, why then do they fail to do so in my example? The reason is that factors of production face competition, indirectly through the goods they produce, not just with identical goods producible with identical factors abroad. Instead, in a world of many goods, complex relationships in demand matter as well. Specifically, in my example a scarce factor competes through trade with goods produced abroad that are not identical to what it produces at home, but are only close substitutes. If these close substitutes happen to be relatively expensive abroad, compared with other goods produced there, then the domestic scarce 
factor may win this competition in spite of its own scarcity. Likewise, if competition through close substitutes pits a domestic abundant factor against other products that are relatively cheap abroad, then its relative return may fall. Since this competition is with different goods whose factor intensities are unrelated to those used at home, knowledge of relative scarcity and abundance of factors alone is not enough to determine how this competition will work itself out.

The particular example below focuses on goods that are close substitutes, but extremes of complementarity in demand no doubt could also lead to similar results. The point is that once one moves beyond the simplicity of a two-good model where interesting patterns of substitutability and complementarity cannot arise, the issue of how factors compete with one another through international trade depends crucially on these aspects of demand. One result of this is that even the tendency toward factor-price equalization is not assured in a general many-good model. This in turn, as I will show in section 3, causes other aspects of economic performance, such as trade itself and real factor incomes, to depart from what one would have expected on the basis of the simple HOS model.

Another implication of these results is that existence or nonexistence of FIRs is not the issue. To clinch this point I show in section 4 that one can turn any model with FIRs into one without, and vice versa, simply by redefining goods. FIRs are meaningful only in the textbook two-good model, where the limited number of goods constrains the relationships that can exist among them. For a many-good model to be well behaved we need some other assumption about preferences, together with technology.

What assumption should this be? I do not know, and I hope others will be induced to look for one by my example. All $I$ offer now is an assumption that is far too extreme: that all utility and production functions are CobbDouglas. In section 5 I show that this assumption guarantees factor-price convergence. Thus my example and its disturbing implications cannot occur in such a Cobb-Douglas world.

\section{The example}

Because Samuelson's (1949) factor-price equalization theorem requires very restrictive assumptions, it would be useful to have a weaker but more generally valid result, such as that factor prices are drawn closer together by trade. $^{2}$ Unfortunately, Land (1959) has shown that this need not be the case. ${ }^{3}$ Here, I provide a more dramatic example of factor-price divergence

\footnotetext{
${ }^{2}$ This was Ohlin's (1933) proposition, which Samuelson (1971) argues is correct in a specificfactors model.

3Johnson (1967) objected that Land's counterexample was inconsistent with equilibrium in all markets. Stewart (1976), however, showed how demands could respond to price differences so as to validate Land's example.
} 
that is simpler and more useful for my later analysis. ${ }^{4}$ In my example, the structure of preferences for four goods leads to behavior like a two-good model with a double FIR, in which factor prices may move apart in opposite directions with trade.

First consider the familiar two-good HOS model with two FIRs. The relationship between relative factor prices, $\omega$, and the relative price of two goods, $p=p_{\mathrm{I}} / p_{\mathrm{II}}$, is S-shaped as in fig. $1 .{ }^{5}$ If factor endowments of two countries, A and B, differ appropriately, then autarky factor prices may be $\omega^{\mathrm{A}}$ and $\omega^{\mathrm{B}}$, as shown. As drawn, the relative autarky price of good I is higher in A, even though good $I$ is locally labor-intensive in both countries and $\mathrm{A}$ is abundantly endowed with labor. ${ }^{6}$ Thus, with trade, as prices of goods come together, prices of factors are driven farther apart.

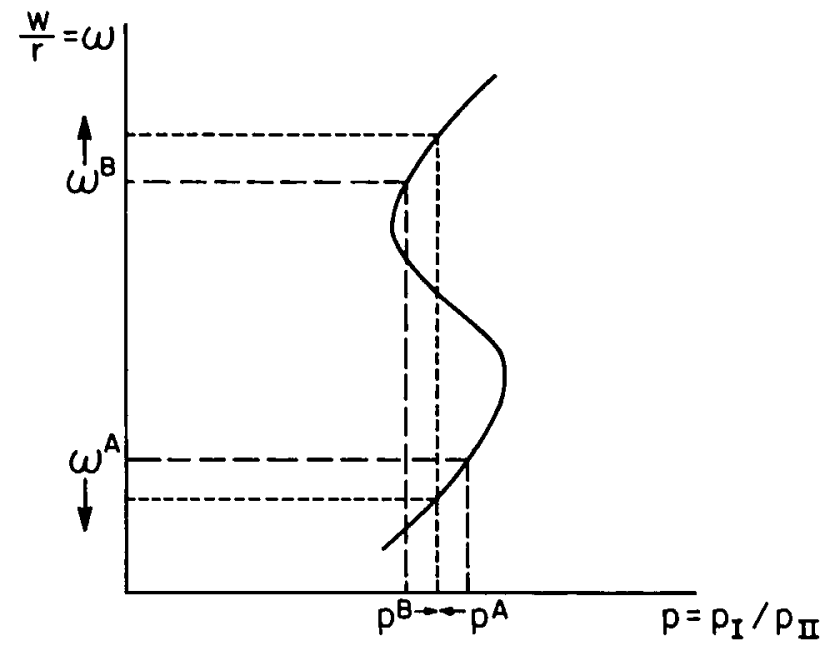

Fig. 1

Now consider a different model, with no FIRs but four goods, whose unit isoquants are those in fig. 2. Suppose the following very special preferences: goods $X_{1}$ and $X_{3}$ are perfect substitutes, as are goods $X_{2}$ and $X_{4}$. With this

${ }^{4}$ In the Land-Stewart counterexample, free trade can lower the wage-rental ratio in both countries, and the fall can be greater where the ratio was initially lower. Comparing these changes may be sensitive to units of measurement. Dixit and Norman (1980, p. 102) mention the difficulty of measuring distance between vectors of factor prices. This difficulty is avoided when factor-price ratios move apart in opposite directions.

${ }^{5}$ See Samuelson (1949) for this relation without FIRs. See Chacholiades (1978, pp. 273-280) and the references cited therein for cases of single and multiple FIRs.

${ }^{6}$ Relative factor intensities determinine the slope of the curve, since a rise in the relative wage raises the relative price of the labor-intensive good. Thus in fig. 1 , good $I$ is labor intensive for both high and low wage-rental ratios, but capital intensive in between. Relative factor abundance can be measured either by relative autarky factor prices or by relative physical endowments. In this case the two definitions agree. 


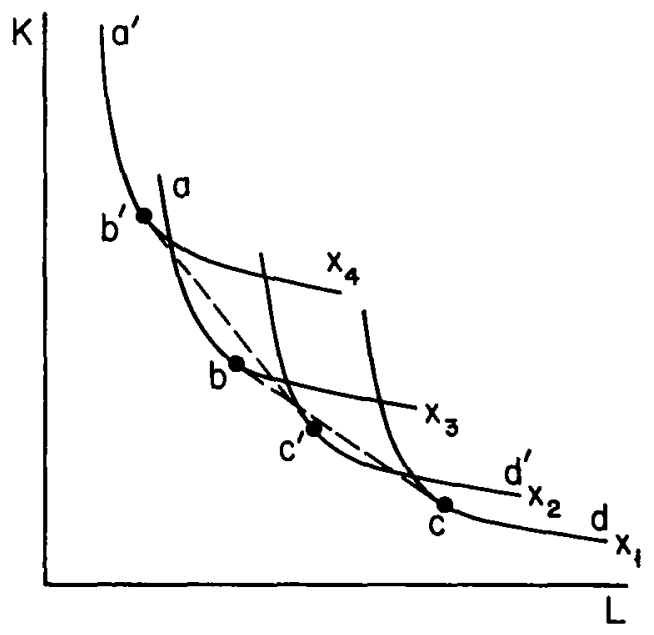

Fig. 2

assumption the two pairs of goods can be aggregated, and the model is equivalent to a model with only two goods.

The feasible inputs for a unit of the $X_{1}-X_{3}$ aggregate include all convex combinations of inputs for producing one unit of $X_{1}$ and one unit of $X_{3}$, thus the convex hull of the separate $X_{1}$ and $X_{3}$ isoquants: the curve abcd. Similarly, the unit isoquant for the $X_{2}-X_{4}$ aggregate is the curve $a^{\prime} b^{\prime} c^{\prime} d^{\prime}$. These two aggregate unit isoquants intersect three times, displaying two FIRs, just as in fig. 1. Thus, the four-good model with these particular pairwise perfect substitutes will behave exactly like the two-good model with a double FIR, and factor prices may diverge with trade, as in fig. 1.

What can happen, more fully, is this. ${ }^{7}$ Since prices of perfect substitutes must be the same, let $p_{1}=p_{3}=p_{1}$ and $p_{2}=p_{4}=p_{\mathrm{II}}$, and call goods $X_{1}$ and $X_{3}$ type I, goods $X_{2}$ and $X_{4}$ type II. In autarky, if country A is sufficiently labor abundant, it will satisfy demands for the two types of goods by producing only $X_{1}$ and $X_{2}$, while with enough more capital country $B$ will produce only $X_{3}$ and $X_{4}$. Furthermore, if A's and B's endowments are sufficiently close to the factor requirements of $X_{2}$ and $X_{3}$, respectively, then the price of type I goods relative to type II goods, $p_{\mathrm{I}} / p_{\text {II }}$ in fig. 1 , will be higher in $\mathrm{A}$ than in $\mathrm{B}$.

When trade is opened up, demanders in A find it cheaper to import $X_{3}$ from B than to buy $X_{1}$ domestically. Likewise, demanders in B import $X_{2}$ from $\mathrm{A}$ to replace domestic production of $X_{4}$. Thus, $\mathrm{A}$ exports $X_{2}$ in exchange for $X_{3}$ from $\mathrm{B}$, and the relative price $p_{\mathrm{I}} / p_{\mathrm{II}}$ falls in $\mathrm{A}$ and rises in $\mathrm{B}$.

${ }^{7}$ The following discussion can be illustrated with an elaboration of Samuelson's diagram relating relative prices of goods and factors to factor intensities. Space does not permit.including that diagram here, but it is available on request. 
Since $X_{2}$ is more capital intensive than $X_{1}$, the fall in $p_{1} / p_{11}=p_{1} / p_{2}$ in $\mathrm{A}$ and the shift of production toward $X_{2}$ causes the wage-rental ratio there to fall, while the opposite happens in $B$.

As resources shift toward the exports of the two countries, output of both $X_{1}$ (in A) and $X_{4}$ (in B) will fall, and one or both of the countries may completely specialize. If this happens in a country, relative factor prices there stop adjusting, but this does not interfere with them having been driven farther apart by trade. ${ }^{8}$

This particular example is made tractable by having goods be perfect substitutes, but a similar result could occur if they were only very close substitutes. What seems to be important is the asymmetry in substitution, goods being closer substitutes for some goods than for others, and the way this asymmetry interacts with factor intensities. ${ }^{9}$

\section{Implications for other theorems of trade}

Implicit in the example of section 2 are several disturbing implications for theorems of the HOS model, besides the factor-price equalization theorem itself.

\subsection{The Heckscher-Ohlin theorem}

One might expect the Heckscher-Ohlin theorem to collapse in this example, but instead, general versions of the theorem are still valid. In Deardorff (1982) I proved two such versions - one for the factor content of trade, the other for its commodity composition - by defining factor content and intensity using country-of-origin production techniques. In the example here, country A exports $X_{2}$ and B exports $X_{3}$, other goods not being traded at all. Each country thus exports a good that is more intensive in the use of its abundant factor than what it imports, and this satisfies the theorem.

However, the example does point out the limited usefulness of the theorem in this form, since it fails to tell what trade will be, starting from autarky. Each country produces only two goods in autarky, and either one could be exported and the other displaced by imports.

Since imports displace production not only of goods identical to themselves, but also of goods that are close substitutes in demand, a theorem cannot tell us how industries will be affected by trade without first considering properties of demand.

\footnotetext{
${ }^{8}$ Complete specialization here is made more likely by the endowments of the two countries being somewhat closer together, since this drives apart their autarky price ratios, $p_{V} / p_{\| 1}$.

${ }^{9}$ The example is consistent with the familiar assumption of internationally identical, homothetic preferences.
} 


\subsection{The Stolper-Samuelson theorem}

At one level, the Stolper-Samuelson theorem is a technical and local relationship between prices of goods and factors, and its validity in a twofactor model depends mainly on whether goods are produced. Generalizations of Stopler-Samuelson, surveyed in Ethier (1984), mostly look for similar local relationships.

At a more intuitive level, however, the theorem says simply that free trade lowers the real wage of the scarce factor, and raises the real wage of the abundant factor, compared to autarky. Since free trade opens factor markets to indirect competition from abroad, the idea that it should cause a lessening of scarcity rents has great appeal. This suggests a more useful generalization of the Stolper-Samuelson theorem in terms of, say, a negative correlation between changes in factor returns and a measure of their relative scarcity.

Unfortunately, even this weak relationship does not hold generally, since it fails in the example here. As long as two goods are produced in a country, real returns still follow relative returns, $\omega$. Since relative returns move apart with trade, so do real returns, and thus real returns to scarce factors rise and real returns to abundant factors fall with trade. The reason is again that factors compete not with identical factors abroad, but rather with whatever factors produce the closest substitutes for what they produce at home.

\subsection{The Rybczynski theorem}

Like its dual, the Stolper-Samuelson theorem, the Rybczynski theorem could have both local and global versions. The global version would be that further accumulation of a country's already abundant factor will worsen its terms of trade, while accumulation of its scarce factor will improve it. This is what happens in the $2 \times 2$ model with no FIRs if both goods are normal in consumption and both are produced, and it seems plausible that the same would happen in higher dimensions. If countries trade embodied factor services, it is natural to think of accumulation of the scarce factor, say, as reducing the demand for imports of its services and thus lowering their price.

Unfortunately, once again, my example indicates that this is not generally true. If country A produces both $X_{1}$ and $X_{2}$ with free trade, then a greater endowment of labor will increase its output of $X_{1}$ and reduce its output of the less labor-intensive $X_{2}$. Since A exports $X_{2}$, this change is therefore ultrabiased against exports and will improve the terms of trade. ${ }^{10}$ Analogously, accumulation of A's scarce factor, capital, will worsen its terms of trade.

How can accumulation of the abundant factor fail to worsen the terms of trade? It is not that such accumulation fails to cheapen the factor itself. Instead, what is happening is a consequence of the unusual pattern of trade. While A's exports are more labor intensive than her actual imports, they are

${ }^{10}$ See Corden (1956). 
not more labor intensive than her import substitutes. When $\mathrm{A}$ accumulates labor, production of import substitutes expands and production for export declines, leading to an improvement in the terms of trade.

\subsection{The Mundell theorem}

A final result to consider is Mundell's (1957) result that trade substitutes for international factor mobility. In the $2 \times 2$ model, in addition to equalizing factor prices, greater trade also reduces the movement of factors, while greater factor movement reduces the volume of trade.

In my example here these results are overturned. Trade moves relative and absolute factor prices farther apart than in autarky and thus increases the incentive for international factor movement. Also, within limits, some international movement of factors increases the volume of trade. Start from free trade with A producing $X_{1}$ and $X_{2}$ and exporting $X_{2}$. If a small amount of labor moves from the low-wage $A$ to high-wage $B$, at initial prices A's outputs of $X_{1}$ will fall and of $X_{2}$ will rise, tending to increase trade. After adjustment of prices to restore equilibrium, it is likely that the new equilibrium will involve larger quantities of $X_{2}$ and $X_{3}$ being exchanged.

\section{Do FIRs really matter?}

In spite of the importance attached to them in the textbook HOS model, the absence of FIRs is neither necessary nor sufficient for the validity of the theorems of trade in higher dimensions. ${ }^{11}$ To emphasize this point I now note that FIRs can be made to appear and disappear at will, just by redefining goods. Thus, FIRs seem to be harmless little beasts in general, and, if they appear, are mere figments of our aggregation. ${ }^{12}$

Suppose first that a FIR exists in the technologies of goods $X$ and $Y$, occurring at capital-labor ratio $k_{0}$, and suppose that at or near $k_{0} \operatorname{good} X$ has the larger elasticity of substitution. ${ }^{13}$ Redefine $X$ as two different goods depending on whether it is produced with more or less capital per worker than $k_{0} \cdot{ }^{14}$ Letting these two goods be perfect substitutes in demand, we now have an exactly equivalent model with no FIRs. ${ }^{15}$

\footnotetext{
${ }^{11}$ That it is not sufficient follows from my example. That it is not necessary is well known even in two dimensions.

${ }^{12}$ For another example of this, see Jones (1974), where a model of many traded goods and one nontraded good without FIRs becomes a two-good model with one FIR when the traded goods are aggregated.

${ }^{13}$ Goods cannot have the same elasticity of substitution over an interval and still have a FIR within that interval.

${ }^{14}$ Let $X$ produced with $k \geqq k_{0}$ be $X^{\prime}$ and $X$ produced with $k<k_{0}$ be $X^{\prime \prime}$. The $X^{\prime}$ and $X^{\prime \prime}$ isoquants are portions of the original $X$ isoquant, supplemented with horizontal or vertical segments beginning at $k_{0}$.

${ }^{15}$ Alternatively, convert each good to a continuum of goods, each using a different and fixed technique of production chosen from the original isoquants.
} 
By a similar procedure, FIRs can be created by redefining goods. Take any good, $X$, with a conventional curved isoquant. Pick two arbitrary capitallabor ratios, $k_{1}$ and $k_{2}$, and define two different goods depending on whether they use the factors in a ratio that is between these or not. That is, define $X$ as $X^{\prime}$ for $k \in\left[k_{1}, k_{2}\right]$ and as $X^{\prime \prime}$ otherwise. The $X^{\prime}$ isoquant will be vertical or horizontal outside this interval, while the $X^{\prime \prime}$ isoquant will have a downwardsloping straight segment within it. With $X^{\prime}$ and $X^{\prime \prime}$ perfect substitutes, these constructed portions of their isoquants will never be used, and the new model will behave exactly like the old model. Yet these two newly defined goods do display a FIR. ${ }^{16}$

Thus, if the definition of a 'good' is flexible, ${ }^{17}$ the concept of a FIR should not play a compelling role in trade theory. The qualifications imposed by FIRs on the theorems of trade are appropriate however, as section 3 makes clear. Unless further analysis suggests an acceptable alternative assumption to the absence of FIRs - one that will get rid of the problems they cause even with many goods - we should take these problems seriously. In fact, I would suggest that FIRs be given increased attention in teaching, since they conveniently illustrate in two dimensions the problems posed by complementarities and substitutabilities in higher dimensions.

\section{An alternative to the absence of FIRs?}

If the absence of FIRs is neither necessary nor sufficient for trade in many dimensions to be well behaved, what alternative assumption might serve the purpose better? Traditionally, extensions of trade theorems have relied on factor-price equalization and incomplete specialization, which in turn require countries to have sufficiently similar endowments. Like Krueger (1977), I find these assumptions to be overly restrictive as descriptions of the world, and they rule out cases I find most interesting. Allowing specialization instead, the problems of section 3 need to be dealt with on their own terms. My example suggests that problems arise when goods are closer substitutes for some goods than for others, and I expect similar problems with analogous variations in complementarity. ${ }^{18}$ To rule these out completely is too restrictive, but may help to start the search for a more empirically acceptable assumption.

Consider, then, a model with two countries, two factors, and any number of goods, $n$. Let all utility and production functions be Cobb-Douglas and

\footnotetext{
${ }^{16}$ Again we could achieve the result with a continuum of goods. Turn just one of two goods into a continuum of goods with fixed techniques, as in the preceding footnote. Each of the new goods displays a FIR relative to the other original good.

${ }^{17}$ Redefining goods would be unacceptable if a particular definition of a 'good' were universally accepted, but this is hardly the case. Nor is differentiating goods on the basis of how they are produced unusual, since this is a common feature of industrial classification systems.

${ }^{18}$ It was complementarities that provided the 'weak link in the chain of comparative advantage' in Deardorf (1979).
} 
identical across countries. ${ }^{19}$ All elasticities of substitution are then unity, and thus such extremes of substitutability as were assumed in section 2 are ruled out. In this Cobb-Douglas world, factor prices must be drawn together by free trade, even when they are not completely equalized.

To see this, note first that Cobb-Douglas preferences and production functions together imply indirect Cobb-Douglas preferences for factors. That is, if consumers spend a fraction $b_{i}$ on good $i$, and if the labor share in producing good $i$ is $a_{i}$, then the fraction of consumer expenditure that is paid to labor producing good $i$ is $c_{i}=a_{i} b_{i}$. Also, for any $n^{\prime} \leqq n$, the fraction of expenditure on the subset of goods $1, \ldots, n^{\prime}$ is constant, as is the fraction $\theta\left(n^{\prime}\right)$ of that that goes in turn to labor,

$$
\theta\left(n^{\prime}\right)=\sum_{i=1}^{n^{\prime}} c_{i} / \sum_{i=1}^{n^{\prime}} b_{i}
$$

The wage-rental ratio of a country in autarky, $\omega_{0}^{j}, j=\mathrm{A}, \mathrm{B}, \mathrm{can}$ be derived by comparing shares of labor and capital, to yield:

$$
\omega_{0}^{j}=\frac{w_{0}^{j}}{r_{0}^{j}}=\frac{\theta(n)}{1-\theta(n)} \frac{K^{j}}{L^{j}}, \quad j=\mathrm{A}, \mathrm{B},
$$

where $K^{j}$ and $L^{j}$ are the respective capital and labor endowments.

With free trade and unequal factor prices, labor-abundant $A$ will produce only goods more labor intensive than those produced in B. ${ }^{20}$ Ranking the goods by labor intensity,

$$
a_{1}>a_{2}>\cdots>a_{n}
$$

one can again compare capital and labor shares to derive

$$
\omega^{\mathrm{A}}=\frac{w^{\mathrm{A}}}{r^{\mathrm{A}}}=\frac{\theta\left(i^{\prime}\right)}{1-\theta\left(i^{\prime}\right)} \frac{K^{\mathrm{A}}}{L^{\mathrm{A}}}
$$

where $i^{\prime}$ is the most capital-intensive good produced only in country $\mathrm{A}^{21}$ The wage-rental ratio in $\mathrm{B}$ with trade, $\omega^{\mathrm{B}}$, is analogous to (4) but with $\theta$ replaced by $(1-\theta)$.

To compare wage-rental ratios, note from (2) that autarky wage-rental ratios depend only on the capital-labor endowment ratios, $K / L$, since $\theta(n)$ is the same in both countries. Thus, $\omega_{0}^{\mathbf{A}}<\omega_{0}^{\mathbf{B}}$, since $\mathrm{A}$ is labor abundant.

${ }^{19}$ Dornbusch, Fischer and Samuelson (1980) use Cobb-Douglas utility and production functions in part of their analysis of the Heckscher-Ohlin model with a continuum of goods.

${ }^{20}$ See Deardorff (1979). A single good, $i_{c}$, may be produced in common.

"If there is a good, $i_{\mathfrak{c}}$, produced in common, then $\omega^{\mathrm{A}}$ lies between that of eq. (4) and the value thal would be obtained replacing $i^{\prime}$ in (4) with $i_{c}$. The argument still goes through. 
Next note in (1) that $\theta\left(n^{\prime}\right)$ is a weighted average of the $a_{i}$ from $i=1, \ldots, n^{\prime}$. From (3) it follows that $\theta\left(n^{\prime}\right)$ declines as $n^{\prime}$ increases. Comparing (2) and (4), since $i^{\prime}<n$, it follows that $\omega_{0}^{\mathrm{A}}<\omega^{\mathrm{A}}$. By similar reasoning for $\mathrm{B}$, one can complete the following chain of inequalities:

$$
\omega_{0}^{\mathbf{A}}<\omega^{\mathbf{A}}<\omega^{\mathbf{B}}<\omega_{0}^{\mathbf{B}}
$$

Thus, wage-rental ratios are drawn closer together by trade in this special Cobb-Douglas model, and none of the problems noted in section 3 arises.

\section{Conclusion}

I view this paper as calling attention to a problem that needs to be solved. The example in section 2 is not implausible, but I doubt that it is representative of the world. The particular pattern of substitutability in the example is quite asymmetric and thus, I suspect, unlikely to occur. What we need is some assumption on preferences and technology together, similar in spirit but less restrictive than the Cobb-Douglas assumption of section 5, that will rule out such an extreme result. I hope that this paper will stimulate others to search for such an assumption.

After decades in which trade theory has focused primarily on properties of production functions, ${ }^{22}$ it is important that we now give equally careful attention to the demand side, of the economy. We have not done so before largely because there is little room for preferences to matter in a two-good model. But as we now extend trade theory into higher dimensions, preferences may come into their own as, if nothing else, an irritating complication in the analysis.

\footnotetext{
${ }^{22}$ See however Jones (1980) who has explored the roles of various assumptions about demand in trade theory. Also, Melvin (1969) has explored implications of a particular demand assumption in a Ricardian model, and Melvin (1983) has looked at taste differences within a country with transport costs.
}

\section{References}

Bhagwati, Jagdish, 1969, The pure theory of international trade: A survey, in: J.N. Bhagwati, Trade, tariffs and growth (M.I.T. Press, Cambridge, MA) 3-122.

Chacholiades, Miltiades, 1978, International trade theory and policy (McGraw-Hill, New York).

Corden, W.M., 1956, Economic expansion and international trade: A geometric approach, Oxford Economic Papers 8.

Deardorff, Alan V., 1979, Weak links in the chain of comparative advantage, Journal of International Economics 9, 197-209.

Deardorff, Alan V., 1982, The general validity of the Heckscher-Ohlin theorem, American Economic Review 72, 683-694.

Deardorff, Alan V., 1983, An example of international factor-price divergence, Research seminar in international economics, Seminar discussion paper no. 116, University of Michigan.

Dixit, Avinash K. and Victor Norman, 1980, Theory of international trade (Cambridge University Press, London). 
Dornbusch, Rudiger, Stanley Fischer and Paul A. Samuelson, 1980, Heckscher-Ohlin trade theory with a continuum of goods, Quarterly Journal of Economics 95, 203-224.

Ethier, Wilfred J., 1984, Higher dimensional issues in trade theory, in: Ronald W. Jones and Peter B. Kenen, eds., Handbook of international economics, vol. I (North-Holland, Amsterdam) 131-184.

Heckscher, E., 1919, The effect of foreign trade on the distribution of income, Ekonomisk Tidskrift, 497-512.

Johnson, Harry G., 1967, The possibility of factor-price equalization when commodities outnumber factors, Economica 34, 282-288.

Jones, Ronald W., 1974, The small country in a many-commodity world, Australian Economic Papers 13, 225-236.

Jones, Ronald W., 1980, Demand behavior and the theory of international trade, in: J.S. Chipman and C.P. Kindleberger, eds., Flexible exchange rates and the balance of payments (North-Holland, Amsterdam).

Krueger, Anne O., 1977, Growth, distortions and patterns of trade among countries, Princeton Studies in International Finance No. 40 (Princeton, NJ).

Land, A.H., 1959, Factor endowments and factor prices, Economica 26, 137-142.

Melvin, James R., 1969, On a demand assumption made by Graham, Southern Economic Journal 36, 36-43.

Melvin, James R., 1983, Domestic taste differences, transportation costs and international trade, in process.

Minhas, B.S., 1962, The homohypallagic production function, factor-intensity reversals and the Heckscher-Ohlin theorem, Journal of Political Economy 60, 138-156.

Mundell, Robert A., 1957, International trade and factor mobility, American Economic Review $47,321-335$.

Ohlin, Bertil, 1933, Interregional and international trade (Harvard University Press, Cambridge, MA).

Rybczynski, T.M., 1955, Factor endowments and relative commodity prices, Economica 22, 336341.

Samuelson, Paul A., 1949, International factor-price equalization once again, Economic Journal 59, 181-197.

Samuelson, Paul A., 1971, Ohlin was right, Swedish Journal of Economics 73, 365-384.

Stern, Robert M., 1975, Testing trade theories, in: Peter B. Kenen, ed., International trade and finance: Frontiers for research (Cambridge University Press, New York) 3-49.

Stewart, Doug, 1976, Can trade widen the difference between factor rewards?, American Economic Review 66, 671-674.

Stolper, Wolfgang and Paul A. Samuelson, 1941, Protection and real wages, Review of Economic Studies 9, 58-73. 